\title{
Evidence for interfacial uptake in hexadecane degradation by Rhodococcus equi: the importance of cell flocculation
}

\author{
Murielle Bouchez-Naïtali, ${ }^{1}$ Denis Blanchet, ${ }^{2}$ Véronique Bardin ${ }^{2}$ \\ and Jean-Paul Vandecasteele ${ }^{2}$
}

Author for correspondence: Murielle Bouchez-Naïtali. Tel: +331699351 40. Fax : +33169935084.
e-mail: naitali@ensia.inra.fr

1 Ecole Nationale Supérieure des Industries Agricoles et Alimentaires, Laboratoire de Microbiologie Industrielle, 91744 Massy Cedex, France

2 Institut Français du Pétrole, Division Chimie et Physico-chimie Appliquées, 92852 Rueil-Malmaison Cedex, France

The kinetics of hexadecane degradation were studied in four strains of Rhodococcus equi that did not produce biosurfactants. The aim was to analyse the characteristics of alkane uptake and their relevance to a mechanism of interfacial uptake. The kinetic studies involved continuous determination of degradation by electrolytic respirometry in a diphasic system where the hydrophobic phase was hexadecane or a solution of hexadecane in a non-toxic, non-biodegradable solvent, either $2,2,4,4,6,8,8$-heptamethylnonane or silicone oil. The technique allowed large variations in interfacial area between the aqueous and hydrophobic phases. For the four strains, the kinetics obtained were reproducible and showed, in almost all cases, an initial short phase of exponential growth, followed by a long phase of linear growth. Specific growth rates during exponential growth varied amongst the strains from 0.11 to $0.20 \mathrm{~h}^{-1}$ and were independent of interfacial area, in accordance with the very strong adsorption of bacterial cells at the interface of solvent and aqueous media. The degradation rates during linear growth did not increase with interfacial area but increased with efficiency of stirring. These characteristics can be explained by the formation of cellular flocs due to the hydrophobicity of the strains. These flocs were observed during growth on hexadecane in almost all conditions. In one case, with a non-flocculating culture, a kinetic pattern with a longer exponential phase, closer to that expected for simple interfacial uptake, was observed. The results show that strictly interfacial uptake, limited by floc formation (occurring at moderate and higher cell densities, and controlled by stirring efficiency) is a common pattern for growth on long-chain alkanes of micro-organisms that do not produce biosurfactants.

Keywords: alkane degradation, electrolytic respirometry, flocculating strains, Rhodoccocus sp., uptake kinetics

\section{INTRODUCTION}

Hydrocarbons of natural origin are widespread in the environment but, because of the massive utilization of petroleum products, they are nowadays strongly involved in environmental pollution. Biodegradation, either naturally occurring (natural attenuation) or by engineered bioremediation, is a key process for the decontamination of polluted areas. The hydrophobic

Abbreviation: $\mathrm{HMN}, 2,2,4,4,6,8$-heptamethylnonane. nature of hydrocarbons has required micro-organisms to develop specific mechanisms of substrate uptake in order to degrade them (Boulton \& Ratledge, 1984; Haferburg et al., 1986; Hommel, 1994; Singer \& Finnerty, 1984). In the case of long-chain alkanes, the micro-organisms sometimes produce biosurfactants, which results in hydrocarbon micelles or small emulsified hydrocarbon globules. If biosurfactants are not produced, direct cell contact with hydrocarbon droplets can take place, involving strictly interfacial hydrocarbon uptake.

Whatever the mechanisms involved, a point which is 
still only partially understood at the present time is the kinetics of long-chain alkane biodegradation. Studies focused on the kinetics of growth of yeasts on n-alkanes were conducted in the seventies and models were proposed to account for the complex kinetic patterns observed (Blanch \& Einsele, 1973; Erickson et al., 1969, 1970; Erickson \& Humphrey, 1969; Gutierrez \& Erickson, 1977; Moo-Young \& Shimizu, 1971; Verkooyen \& Rietma, 1980a, b; Yoshida \& Yamane, 1974). However, with other alkane-degrading micro-organisms, the interest was essentially oriented towards the production of biosurfactants and kinetic studies are scarce. In a recent work, we analysed the relative distribution of the modes of substrate uptake in a large series of bacterial strains degrading hexadecane $\left(\mathrm{C}_{16}\right)$ (Bouchez-Naitali et al., 1999). In the present work, we studied in detail the kinetics of degradation of $\mathrm{C}_{16}$ by four Rhodococcus strains that had been identified as using direct interfacial uptake on the basis of the absence of biosurfactant production. Cell flocculation was found to constitute an important characteristic of the cultures of these strains on $\mathrm{C}_{16}$. The kinetic patterns of degradation were investigated in relation to the various phenomena involved in $\mathrm{C}_{16}$ uptake.

\section{METHODS}

Culture media. Vitamin-supplemented mineral salt medium MSM4 was as previously described (Bouchez-Naïtali et al., 1999). Mineral salt medium MSM3 was similar, except that the nitrogen source was $1.5 \mathrm{~g} \mathrm{l}^{-1}\left(\mathrm{NH}_{4}\right)_{2} \mathrm{SO}_{4}$ instead of the $\mathrm{KNO}_{3}$ used in MSM4.

Strains. Four Rhodococcus equi strains were employed: NapRu1, HdGe1, PyrGe1 and Fo2. They were isolated from soils as previously described (Bouchez-Naïtali et al., 1999) and were able to use $\mathrm{C}_{16}$ as sole source of carbon and energy.

Cultures in flasks. Cultures were carried out in $250 \mathrm{ml}$ flasks containing $100 \mathrm{ml}$ medium and incubated on a rotary shaker (160 r.p.m.) at $30^{\circ} \mathrm{C}$. They were used as inocula for fermentation work and kinetic studies in the conditions described below. Flask cultures were also used for hydrophobicity determinations. In this case, the medium was MSM3 and the carbon source was $\mathrm{C}_{16}$ (alone or in the hydrophobic solvents studied).

Growth on hexadecane in laboratory fermenters. Batch cultures were performed in 2 litre fermenters (Inceltech), in 1.47 litre MSM4 with $30 \mathrm{ml} \mathrm{C}_{16}$ as sole source of carbon and energy. The inoculum was grown in the same medium containing succinate as carbon source. To remove the residual carbon source from the inoculum, $30 \mathrm{ml}$ of culture was centrifuged $(10000 \mathrm{~g}, 10 \mathrm{~min})$ and the cells were resuspended in $30 \mathrm{ml}$ fresh MSM4 before inoculation of the fermenters. The fermentation conditions were: temperature, $30^{\circ} \mathrm{C}$; stirring speed, 500 r.p.m.; aeration, 1 vol. vol. ${ }^{-1} \mathrm{~min}^{-1}$. The $\mathrm{pH}$ was recorded but not regulated. Experiments were run in duplicate.

Kinetic studies by respirometry. Time courses of oxygen consumed during growth on $\mathrm{C}_{16}$ were recorded using a sensitive respirometer (D12-S Sapromat, Voith) consisting of 12 conical flasks $(500 \mathrm{ml})$ placed in a water bath maintained at $30{ }^{\circ} \mathrm{C}$ (Bouchez et al., 1997a). Determination of electrolytically produced oxygen supplied to the cultures at constant pressure allowed quasi-continuous recording of oxygen consumption. The stirring speed being uniform (300 r.p.m.), two types of stirrers were employed in order to modify agitation efficiency: triangular-section bars $(14 \times 55 \mathrm{~mm})$ in most cases, and smaller, round-section bars $(6 \times 20 \mathrm{~mm})$ when specified. Culture flasks containing $237.5 \mathrm{ml}$ MSM3 were inoculated with $12.5 \mathrm{ml}$ of a preculture on MSM3 supplemented with succinate prepared as above. $\mathrm{C}_{16}$ was added alone or as a solution in a hydrophobic solvent, either 2,2,4,4,6,8,8-heptamethylnonane (HMN) or silicone oil 47V20 (Prolabo). Both solvents were non-toxic and non-water-soluble, and were not degraded by the strains. As indicated in the results, experiments were run several times but individual recordings are presented in the figures. Oxygen consumption blanks (inoculated flasks containing hydrophobic solvent without $\mathrm{C}_{16}$ and uninoculated flasks containing $\mathrm{C}_{16}$ and hydrophobic solvent) were run simultaneously. No significant oxygen consumption was detected in these blanks.

Parameters describing the kinetics obtained in different conditions were compared using analysis of variance. When considered as significantly different $(P<0.05)$ or very significantly different $(P<0 \cdot 01)$, Student's $t$-tests were performed.

Analyses. Analyses were performed as described by BouchezNaïtali et al. (1999). Interfacial tension against $\mathrm{C}_{16}$ and surface tension were determined at $30^{\circ} \mathrm{C}$ on filtered supernatant fluids of cultures by, respectively, the De Nouy ring and Wilhemy plate methods, using a K-12 tensiometer (Krüss). Each result was the mean of ten determinations and standard deviation was less than $0.4 \mathrm{mN} \mathrm{m}^{-1}$. Cell hydrophobicity was measured by the bacterial adherence to hydrocarbon test according to a method adapted from Rosenberg et al. (1980). Hydrophobicity was measured with respect to the hydrophobic phase used in the cultures: $\mathrm{C}_{16}$ when employed alone, or HMN or silicone oil. For each sample, three independent determinations were made and the standard deviation was within $5 \%$. Residual nitrate concentration was determined in culture supernatant fluids using a commercial kit (Boehringer Mannheim). Glycosides were evaluated on supernatant fluids of cultures by the colorimetric method of Dubois et al. (1956) using glucose as standard. Each result was the mean of three determinations and the standard deviation was within $5 \%$.

\section{RESULTS}

\section{Floculating properties of strains degrading hexadecane}

Four Rhodococcus strains, NapRu1, HdGe1, PyrGe1 and Fo2, were selected as non-producers of biosurfactants (Bouchez-Naïtali et al., 1999). Visual and microscopic observations of shake-flask cultures of the strains grown on $\mathrm{C}_{16}$ alone or on $\mathrm{C}_{16}$ dissolved in $\mathrm{HMN}$ or silicone oil were made. In all cases except one, a distinct but more or less pronounced tendency to produce flocs, exhibiting various sizes and consistencies depending on the strains and on the conditions of $\mathrm{C}_{16}$ supply, was observed (Table 1). Upon decanting, cell biomass accumulated as pellets floating above an aqueous phase. Microscopic examination showed that most bacterial cells were found around oil drops or as aggregates in the hydrophobic phase. This can be related to the high hydrophobicity of the cells (Table 1). A 
Table 1. Aggregation properties of Rhodococcus strains during degradation of hexadecane

\begin{tabular}{|llcc|}
\hline Strain & Solvent phase & $\begin{array}{c}\text { Floc } \\
\text { formation* }\end{array}$ & $\begin{array}{c}\text { Cell } \\
\text { hydrophobicity }\end{array}$ \\
\hline NapRu1 & HMN & + & $99 \pm 1$ \\
& $\mathrm{C}_{16}$ & + & $96 \pm 1$ \\
HdGe1 & Silicone oil & + & $81 \pm 1$ \\
Fo2 & Silicone oil & + & $97 \pm 2$ \\
& $\mathrm{C}_{16}$ & + & $95 \pm 2$ \\
PyrGe1 & $\mathrm{C}_{16}$ & + & $93 \pm 2$ \\
& Silicone oil $^{*}$ & - & $77 \pm 2$ \\
\hline
\end{tabular}

* +, Flocs observable by visual and microscopic examination; -, no flocs observed.

$\dagger$ Values are means $\underline{ \pm} \mathrm{sD}$.

different situation was observed with strain PyrGe1 when grown on $\mathrm{C}_{16}$ dissolved in silicone oil. In these conditions, this strain formed visually homogeneous cultures with a large proportion of bacteria dispersed in the aqueous medium. This strain exhibited a lower cell hydrophobicity when growing on $\mathrm{C}_{16}$ dissolved in silicone oil $(77 \%)$ than on $\mathrm{C}_{16}$ alone $(93 \%)$.

\section{Kinetic study of growth of flocculating strains on hexadecane}

Several properties of cultures relating to the mode of substrate uptake are presented in Fig. 1 for strain NapRu1 during growth in fermenters with $\mathrm{C}_{16}$ as sole source of carbon and energy and nitrate as limiting nitrogen source. Determination of residual nitrate was selected in order to follow the growth of the culture as both biomass accretion and $\mathrm{C}_{16}$ consumption measurements were hindered by heterogeneous dispersion in the medium. All the nitrate was consumed, which corresponded to a biomass production of about $5 \mathrm{~g} \mathrm{l}^{-1}$ (assuming a nitrogen/biomass ratio of $10 \%$ ). The results also show that during the growth period, cell hydrophobicity remained high, an important characteristic for efficient interfacial uptake. Interfacial and surface tensions of culture supernatant fluids also remained high, proving the absence of surfactant production, even in conditions of nitrogen limitation which are known to promote biosurfactant production (Desai \& Banat, 1997). This strongly suggests that strain NapRu1 utilized $C_{16}$ by a strictly interfacial uptake mechanism.

A kinetic study of $\mathrm{C}_{16}$ degradation by strain NapRu1 was carried out. An excess of ammonium sulfate was used as nitrogen source. Time courses of oxygen uptake during degradation were recorded in respirometric flasks. Continuous monitoring of oxygen consumption is well suited to kinetic studies in heterogeneous media as oxygen consumed was shown to be proportional to the substrate consumed and to the biomass produced (Bouchez et al., 1997a). The experimentation covered a range of conditions, as presented in Table 2 . $\mathrm{C}_{16}$, used as sole source of carbon and energy, was added alone or dissolved in $\mathrm{HMN}$, and the effects of variations in initial concentations of $\mathrm{C}_{16}$, in volumes of $\mathrm{HMN}$ and in stirring efficiencies were tested. These conditions resulted in changes in the interfacial area between the hydrophobic and aqueous phases, a key parameter in interfacial uptake (Westgate et al., 1995). Examples of the time courses of oxygen consumption curves obtained are presented in Fig. 2. Kinetic analysis of the curves by plotting the oxygen consumed versus time in a semilogarithmic scale led to characterization of a first short phase of exponential growth with a good correlation coefficient $\left(0.9937<r^{2}<0.9999\right)$. This phase represented around $10 \%$ of total growth (expressed as the percentage of total oxygen consumed) when the initial $\mathrm{C}_{16}$ concentration was $1000 \mathrm{mg} \mathrm{l}^{-1}$, irrespective of the volume of the solvent phase. The maximal specific growth rate $(\mu)$ of strain NapRu1 growing on $\mathrm{C}_{16}$ (Table 2) was not dependent on the conditions tested as shown by an analysis of variance $(P=0 \cdot 96)$. A mean $\mu$ value of $0 \cdot 20 \pm 0 \cdot 02 \mathrm{~h}^{-1}$ was recorded for all the conditions. After the first exponential phase, a phase of limited growth was observed in all cases: when plotting the oxygen consumed versus time on a direct scale, portions of straight lines were obtained with excellent correlation coefficients $\left(0.9985<r^{2}<0.9999\right)$. The values of linear $\mathrm{O}_{2}$ consumption rates are presented in Table 2. A Student's $t$-test performed on these values after analysis of variance showed that they were significantly different $(P<0.05)$ when the stirring efficiency varied, but not when the volume of the solvent phase and the initial concentration of $\mathrm{C}_{16}$ were varied. Rate values were $16 \pm 1 \mathrm{mg} \mathrm{O}_{2} \mathrm{l}^{-1} \mathrm{~h}^{-1}$ when small magnetic bars were used and a mean of $30 \pm 3 \mathrm{mg} \mathrm{O} \mathrm{O}^{-1} \mathrm{~h}^{-1}$ in other conditions.

The kinetics of growth of strains HdGe1, PyrGe1 and Fo2 in flocculating conditions (Table 1) were studied for comparison with strain NapRu1. Kinetic patterns similar to those presented for strain NapRu1 were obtained and Table 3 summarizes the resulting data. An initial exponential phase was clearly observed $\left(0.9857<r^{2}<\right.$ 0.9991 ) during $5 \%$ of the growth period for strains HdGe1 and PyrGe1 and during $10 \%$ of the growth period for strain Fo2, when $\mathrm{C}_{16}$ was added at the initial concentration of $1000 \mathrm{mg} \mathrm{l}^{-1}$. For all strains, the maximum specific growth rates were not dependent on the conditions tested $(P>0.37$ in all cases in analyses of variance performed on $\mu$ values of each of the different strains). It is notable that strains $\mathrm{HdGe} 1$ and Fo2 grew at a rate $\left(0 \cdot 18 \pm 0 \cdot 01 \mathrm{~h}^{-1}\right.$ in both cases) similar to that of strain NapRu1, whereas strain PyrGe1 showed a lower $\mu$ value $\left(0 \cdot 13 \pm 0.01 \mathrm{~h}^{-1}\right)$. A second phase of limited growth was again observed. In most cases, it was linear $\left(0.9987<r^{2}<0.9999\right)$. For a given strain, the linear $\mathrm{O}_{2}$ consumption rates, when observed, were found not to be dependent on the conditions tested $(P>0.52$ in all 


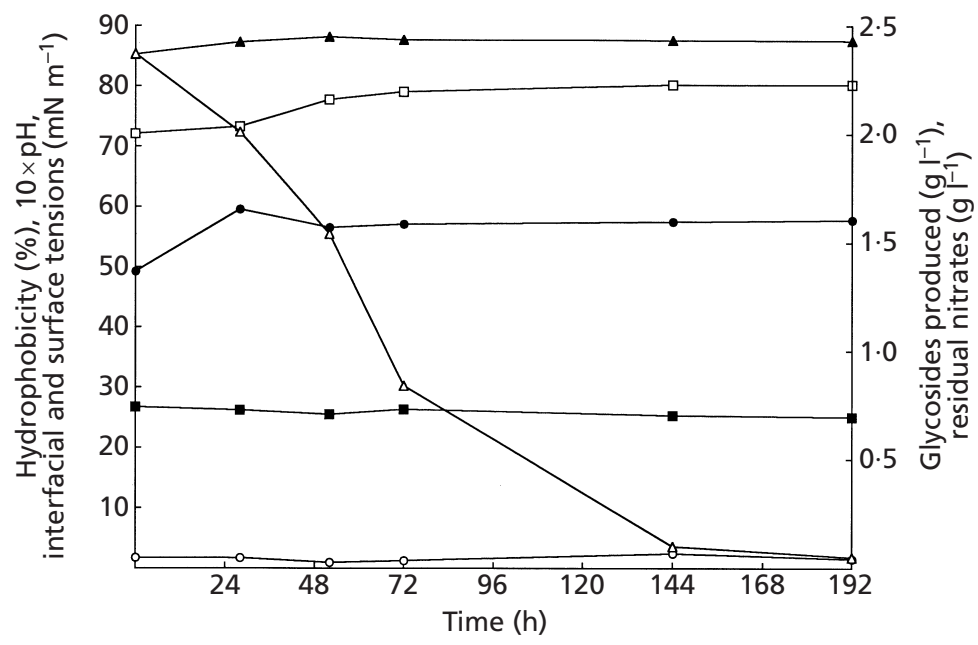

Fig. 1. Cultural characteristics of $R$. equi NapRu1 during growth on hexadecane in a fermenter. Surface tension and $\mathbf{\square}$, interfacial tension of culture supernatants; $\bigcirc$, glycosides produced; $\boldsymbol{\Delta}$, cell hydrophobicity; $\triangle$, residual nitrate; $\square, \mathrm{pH}$.

Table 2. Kinetic constants for the two phases of hexadecane degradation by $R$. equi NapRu1

The maximal specific growth rate $(\mu)$ and the oxygen uptake rate during the linear growth phase were determined under various experimental conditions.

\begin{tabular}{|ccccc|}
\hline $\begin{array}{l}\text { HMN } \\
\text { volume } \\
(\mathrm{ml})\end{array}$ & $\begin{array}{c}\text { Concn of } \mathrm{C}_{16} \\
{[\mathrm{mg}(\mathbf{l} \text { aqueous }} \\
\left.\text { phase })^{-1}\right]\end{array}$ & Replicates* & $\boldsymbol{\mu}\left(\mathbf{h}^{-1}\right) \dagger$ & $\begin{array}{c}\text { Rate of linear } \\
\text { oxygen uptake } \\
\left(\mathrm{mg} \mathrm{O}_{2} \mathbf{l}^{-1} \mathbf{h}^{-1}\right) \dagger\end{array}$ \\
\hline 0 & 1000 & 4 & $0 \cdot 23 \pm 0 \cdot 03$ & $28 \pm 2$ \\
0 & 6160 & 2 & $0 \cdot 19 \pm 0 \cdot 01$ & $29 \pm 1$ \\
0 & 30800 & 2 & $0 \cdot 19 \pm 0 \cdot 01$ & $28 \pm 0$ \\
0 & 67760 & 1 & $0 \cdot 23$ & 28 \\
5 & 1000 & 2 & $0 \cdot 22 \pm 0 \cdot 01$ & $28 \pm 1$ \\
11 & 1000 & 7 & $0 \cdot 20 \pm 0 \cdot 02$ & $31 \pm 3$ \\
22 & 1000 & 7 & $0 \cdot 19 \pm 0 \cdot 02$ & $31 \pm 3$ \\
44 & 1000 & 4 & $0 \cdot 21 \pm 0 \cdot 03$ & $30 \pm 2$ \\
$0 \neq$ & $6160 \neq$ & $2 \neq$ & $0 \cdot 21 \pm 0 \cdot 01 \neq$ & $16 \pm 1 \neq \mathbb{S}$ \\
\hline
\end{tabular}

*In respirometric flasks as described in Methods.

+ Values are means \pm range when two experiments were carried out, and means \pm SD in other cases.

$\ddagger$ Stirring carried out with smaller magnetic bars than in other experiments to reduce agitation efficiency.

$\$$ Significantly different from other rates as determined by a Student's $t$-test $(P<0 \cdot 05)$.

cases in analyses of variance performed for each strain) and depended only on the strain (Table 3). Specific dependence on the strain was also observed for the span of this linear phase, corresponding to $70 \%$ of the growth period for strains HdGe1 and Fo2 and $50 \%$ for strain PyrGe1 (data not shown).

\section{Kinetics of growth of non-flocculating cultures on hexadecane}

The kinetics of degradation of $\mathrm{C}_{16}$ in silicone oil by strain PyrGe1 monitored with the respirometer (Fig. 3) were quite different from those obtained with flocculating cultures. A long exponential phase was observed during at least $40 \%$ of the degradation period and the maximum specific growth rate appeared to depend on the volume of the hydrophobic phase $(0 \cdot 11$, 0.13 and $0.15 \mathrm{~h}^{-1}$ for volumes of 2, 10 and $50 \mathrm{ml}$, respectively). Linear growth was observed in a second phase for silicone oil volumes of 2 and $10 \mathrm{ml}$. For a silicone oil volume of $50 \mathrm{ml}$, the specific growth rate decreased in a second phase but no linear growth was observed. In these cultures, no clear relationship between the pattern of the second phase of growth and the volume of the organic phase was observed. 


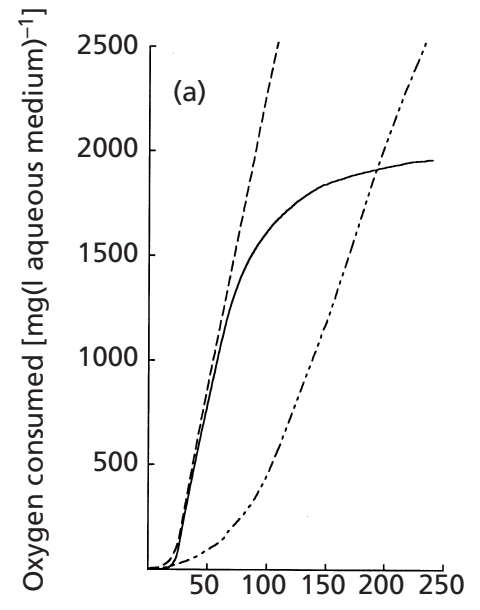

Time $(\mathrm{h})$

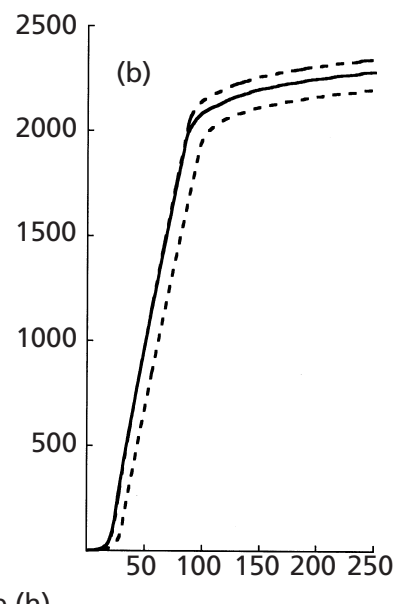

$50 \quad 100150200250$
Fig. 2. Time courses of oxygen consumption during hexadecane degradation by $R$. equi NapRu1. Experiments were conducted in respirometric flasks as described in Methods. (a) $\mathrm{C}_{16}$ was added alone at concentrations of $1000 \mathrm{mg} \mathrm{I}^{-1}(\longrightarrow)$, or $6160 \mathrm{mg} \mathrm{I}^{-1}$ with a normal-sized magnetic stirrer (---) or with a smaller stirrer to reduce agitation efficiency $(\cdot-\cdot)$. (b) $C_{16}\left(1000 \mathrm{mg} \mathrm{I}^{-1}\right.$, expressed with respect to the volume of the aqueous phase) was added dissolved in $5 \mathrm{ml}(---), 11 \mathrm{ml}$ $(-)$ or $22 \mathrm{ml}(\cdot-\cdot)$ HMN.

Table 3. Kinetic constants for the two phases of hexadecane degradation by various flocculating $R$. equi strains

\begin{tabular}{|c|c|c|c|c|c|}
\hline Strain & $\begin{array}{l}\text { Silicone oil } \\
\text { volume }(\mathrm{ml})\end{array}$ & $\begin{array}{c}\text { Concentration of } \\
\mathrm{C}_{16}[\mathrm{mg}(1 \text { aqueous } \\
\left.\text { phase })^{-1}\right]\end{array}$ & Replicates* & $\boldsymbol{\mu}\left(\mathbf{h}^{-1}\right) \dagger$ & $\begin{array}{c}\text { Rate of linear } \\
\text { oxygen uptake } \\
\left(\mathrm{mg} \mathrm{O}_{2} 1^{-1} h^{-1}\right) \dagger\end{array}$ \\
\hline \multirow[t]{3}{*}{ HdGe1 } & 2 & 1000 & 2 & $0 \cdot 19 \pm 0 \cdot 01$ & $28 \pm 3$ \\
\hline & 10 & 1000 & 2 & $0 \cdot 18 \pm 0 \cdot 02$ & $27 \pm 2$ \\
\hline & 50 & 1000 & 1 & $0 \cdot 19$ & 28 \\
\hline \multirow[t]{5}{*}{ Fo2 } & 2 & 1000 & 2 & $0 \cdot 17 \pm 0 \cdot 01$ & $19 \pm 2$ \\
\hline & 10 & 1000 & 3 & $0 \cdot 19 \pm 0 \cdot 01$ & $20 \pm 1$ \\
\hline & 0 & 6160 & 2 & $0 \cdot 18 \pm 0 \cdot 01$ & $18 \pm 1$ \\
\hline & 0 & 30800 & 2 & $0 \cdot 18 \pm 0 \cdot 00$ & Noneł \\
\hline & 0 & 61600 & 2 & $0 \cdot 19 \pm 0 \cdot 02$ & Nonef \\
\hline \multirow[t]{2}{*}{ PyrGe1 } & 0 & 6160 & 4 & $0 \cdot 12 \pm 0 \cdot 01$ & $21 \pm 2$ \\
\hline & 0 & 30800 & 3 & $0 \cdot 13 \pm 0 \cdot 01$ & $23 \pm 3$ \\
\hline
\end{tabular}

*In respirometric flasks as described in Methods.

†Values are means \pm range when two experiments were carried out, and means \pm SD in other cases. $\ddagger$ Non-linear limited growth.

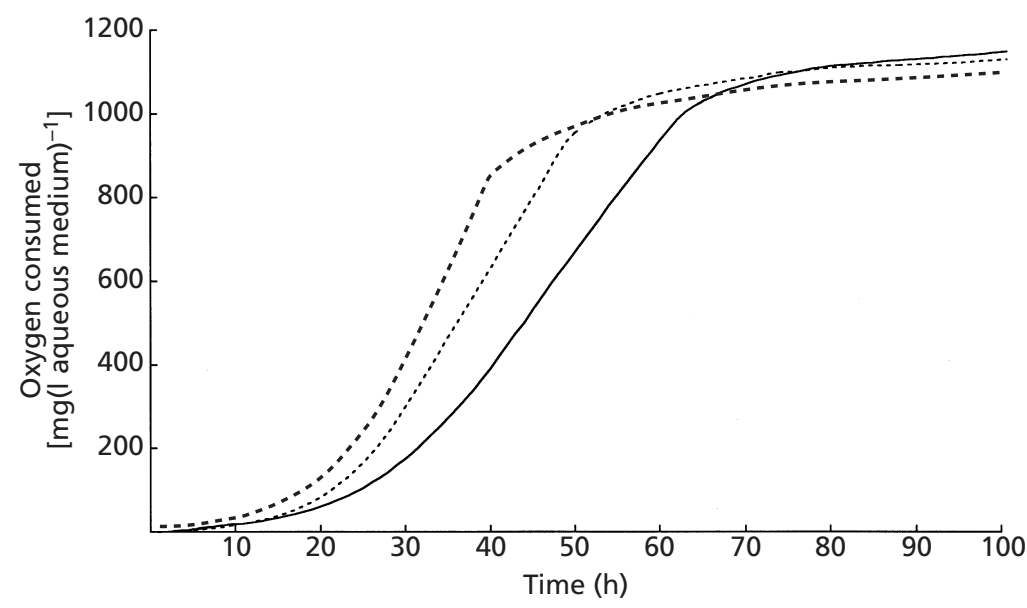

Fig. 3. Time courses of oxygen consumption during hexadecane degradation by $R$. equi PyrGe1. $C_{16}$ (1000 $\mathrm{mg} \mathrm{I}^{-1}$, expressed with respect to the volume of the aqueous phase)

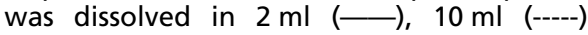
and $50 \mathrm{ml} \mathrm{(--)}$ silicone oil. Experiments were conducted in respirometric flasks as described in Methods. 


\section{DISCUSSION}

This study illustrates the convenience of respirometry to obtain detailed kinetic data on substrate degradation. Moreover, the use of a diphasic system with the hydrophobic substrate dissolved in an inert organic solvent is, as pointed out by Westgate et al. (1995) and by Bouchez (1995), a valuable technique to study interfacial uptake as it allows the characterization of the dependence of uptake on the volume of solvent, i.e. on interfacial area. In an interfacial model of uptake such as that proposed by Dunn (1968), there is an equilibrium between the bacterial cells adsorbed at the interface of hydrophobic and aqueous phases and the cells in the aqueous medium. Only the bacteria with access to the interface can take up the alkane and grow. Growth is exponential until the interfacial area is covered with cells. For this reason, exponential growth lasts longer when greater interfacial area is available. Moreover, the specific growth rate during exponential growth is higher for larger interfacial areas unless cell adsorption at the interface is so strong that practically all cells are adsorbed at the interface. When all the interfacial area is covered with cells, a second phase where growth is linear is observed. During linear growth, the rate will be higher for larger interfacial areas which can support greater amounts of growing biomass. The dependence on interfacial area was well illustrated in a previous study of the interfacial uptake kinetics of pyrene by a Rhodococus strain (Bouchez et al., 1997b). In the present study, the degradation kinetics of $\mathrm{C}_{16}$ corresponded to the model for interfacial uptake only in the case of PyrGe1 growing on $\mathrm{C}_{16}$ in silicone oil, where a long exponential phase was observed. The specific growth rates measured during this phase were found to be higher in cultures with larger solvent volumes. The characteristics of the cultures of strain PyrGe1 on $\mathrm{C}_{16}$ in silicone oil were in good agreement with the growth kinetics observed. The culture was not flocculent and cell adsorption at the interface of solvent and aqueous medium was partial.

A different situation, however, prevailed in other cases. Flocculation of the cultures was always observed. Here, the model for interfacial uptake can account for the existence of a first phase of exponential growth. Higher solvent volumes did not increase the values of the specific growth rates, but this can be explained by the strong adsorption of the bacteria to their substrate, a well-recognized property of many alkane-degrading micro-organisms (Rosenberg, 1992). The interfacial uptake model, however, did not account for the fact that the exponential phase was very short and that the degradation rate during the subsequent phase of linear growth was not dependent on the solvent volume. The biological flocs formed were likely to be responsible for these characteristics. Indeed, a similar situation was discussed by Blanch \& Einsele (1973) in the case of growth of the yeast Candida tropicalis on $\mathrm{C}_{16}$. In flocs, contact with hydrocarbon or dissolved oxygen is ratelimiting for cells inside the aggregates. Interfacial substrate uptake in this case is no longer controlled by the parameters that modify the aqueous and solvent interface (such as the volume of the solvent phase) but by those that modify floc formation, since floc size determines cell access to the substrate. In such a case, stirring is a key parameter because it controls floc size, higher stirring rates promoting smaller flocs and thus higher transfer rates. This point is in agreement with the slower degradation kinetics observed in conditions of lower stirring efficiency. Cell aggregation can explain the onset of the linear phase. The tendency of the cells to agglomerate in flocs increases with increasing biomass. The transition occurs when agglomeration predominates over the turbulence of the medium, which breaks the floc particles. Growth in cell aggregates accounts for the long linear phase of degradation observed with these cultures. Differences in degradation rates during this phase appear to be essentially related, for a given rate of stirring, to differences in cell aggregation properties among strains. The floc formation observed here in almost all cases with Rhodococcus strains leads us to suggest that the analysis given by Blanch \& Einsele (1973) for C. tropicalis may be commonly applicable to micro-organisms growing on long-chain alkanes by strictly interfacial uptake. Actually, the propensity to aggregate appears quite significant among alkane-degrading micro-organisms and is obviously related to the high cell hydrophobicity of the strains concerned. Non-flocculent PyrGe1 cultures corresponded to the lowest values of cell hydrophobicity. In fact, because of their hydrophobicity, all our strains except HdGe1 exhibited some cell agglomeration in cultures on soluble substrates such as succinate, glucose or glycerol, and the growth kinetics of strain NapRu1 on glucose did not show a regular exponential growth pattern. However, growth of these strains on hexadecane clearly promoted cell aggregation.

Thus, the studies confirmed the diagnosis of an interfacial uptake mechanism for the four strains studied, but showed that aggregation of these hydrophobic cells was a major parameter that determined the degradation kinetics. For one strain, PyrGe1, interfacial uptake was either controlled or not by floc formation depending the organic phase used. The results help to clarify the hitherto insufficiently understood characteristics of interfacial uptake of alkanes. The phenomenon of flocculation has significant ecological implications. It is also important for biotechnological applications. The case of micro-organisms producing biosurfactants is quite different, not only because biosurfactants promote the dispersion of the hydrophobic substrate as emulsions or as micelles, but also because they affect cell hydrophobicity and bacterial adherence to hydrocarbons, as shown by Zhang \& Miller (1994) for Pseudomonas aeruginosa.

\section{ACKNOWLEDGEMENTS}

We thank Bertrand Heyd for performing and interpreting statistic analyses. We also thank Hanintsoa Rakotozafy for fermentations on hexadecane and Anne Regourd for cell hydrophobicity measurements. 


\section{REFERENCES}

Blanch, H. W. \& Einsele, A. (1973). The kinetics of yeast growth on pure hydrocarbons. Biotechnol Bioeng 15, 861-877.

Bouchez, M. (1995). La biodégradation des hydrocarbures aromatiques polycycliques: métabolisme de substrats non conventionnels. Doctorate Thesis, Ecole Nationale des Industries Agricoles et Alimentaires, Massy, France.

Bouchez, M., Blanchet, D., Besnainou, B., Leveau, J. \& Vandecasteele, J.-P. (1997a). Kinetic studies of biodegradation of insoluble compounds by continuous determination of oxygen consumption. J Appl Microbiol 82, 310-316.

Bouchez, M., Blanchet, D. \& Vandecasteele, J.-P. (1997b). An interfacial uptake mechanism for the degradation of pyrene by a Rhodococcus strain. Microbiology 143, 1087-1093.

Bouchez-Naïtali, M., Rakatozafy, H., Marchal, R., Leveau, J. Y. \& Vandecasteele, J.-P. (1999). Diversity of bacterial strains degrading hexadecane in relation to the mode of substrate uptake. J Appl Microbiol 86, 421-428.

Boulton, C. A. \& Ratledge, C. (1984). The physiology of hydrocarbon-utilizing microorganisms. In Enzyme and Fermentation Biotechnology, pp. 11-77. Edited by A. Wieseman. New York: Wiley.

Desai, J. D. \& Banat, I. M. (1997). Microbial production of surfactants and their commercial potential. Microbiol Mol Biol Rev 61, 47-64.

Dubois, M., Gilles, K. A., Hamilton, J. K., Rebers, P. A. \& Smith, T. (1956). Colorimetric method for determination of sugars and related substances. Anal Chem 28, 350-356.

Dunn, I. J. (1968). An interfacial kinetics model for hydrocarbon oxidation. Biotechnol Bioeng 10, 891-894.

Erickson, L. E. \& Humphrey, A. E. (1969). Growth models of cultures with two liquid phases. II. Pure substrate in dispersed phase. Biotechnol Bioeng 11, 467-487.

Erickson, L. E., Humphrey, A. E. \& Prokop, A. (1969). Growth models of cultures with two liquid phases. I. Substrate dissolved in dispersed phase. Biotechnol Bioeng 11, 440-466.

Erickson, L. E., Fan, L. T., Shah, P. S. \& Chen, M. S. K. (1970). Growth models of cultures with two liquid phases. IV. Cell adsoption, drop size, and batch growth. Biotechnol Bioeng 12, $713-746$
Gutierrez, J. R. \& Erickson, L. E. (1977). Hydrocarbon uptake in hydrocarbon fermentations. Biotechnol Bioeng 19, 1331-1339.

Haferburg, D., Hommel, R., Claus, R. \& Kleber, H. P. (1986). Extracellular microbial lipids as biosurfactants. Adv Biochem Eng Biotechnol 33, 53-93.

Hommel, R. K. (1994). Formation and function of biosurfactants for degradation of water-insoluble substrates. In Biochemistry of Microbial Biodegradation, pp. 63-87. Edited by C. Ratledge. Dordrecht: Kluwer.

Moo-Young, M. \& Shimizu, T. (1971). Hydrocarbon fermentations using Candida lipolytica. II. A model for cell growth kinetics. Biotechnol Bioeng 13, 761-778.

Rosenberg, E. (1992). The hydrocarbon-oxidizing bacteria. In The Procaryotes, 2 nd edn, pp. 446-459. Edited by A. Balows, H. G. Trüper, M. Dworkin, W. Harder \& K.-H. Schleifer. New York: Springer.

Rosenberg, M., Gutnick, D. \& Rosenberg, E. (1980). Adherence of bacteria to hydrocarbons: a simple method for measuring cell surface hydrophobicity. FEMS Microbiol Lett 9, 29-33.

Singer, M. E. \& Finnerty, W. R. (1984). Microbial metabolism of straight-chain and branched alkanes. In Microbial Metabolism of Straight-Chain and Branched Alkanes, pp. 1-60. Edited by R. M. Atlas. New York: Macmillan.

Verkooyen, A. H. M. \& Rietma, K. (1980a). Growth of yeast on nalkanes. I. Stochastic model. Biotechnol Bioeng 22, 571-595.

Verkooyen, A. H. M. \& Rietma, K. (1980b). Growth of yeast on nalkanes. III. Batch experiments. Biotechnol Bioeng 22, 615-637.

Westgate, S., Bell, G. \& Halling, P. J. (1995). Kinetics of uptake of organic liquid substrates by microbial cells: a method to distinguish interfacial contact and mass-transfer mechanisms. Biotechnol Lett 17, 1013-1018.

Yoshida, F. \& Yamane, T. (1974). Continuous hydrocarbon fermentation with colloidal emulsion feed. A kinetic model for two-liquid phase culture. Biotechnol Bioeng 16, 635-657.

Zhang, Y. \& Miller, R. M. (1994). Effect of a Pseudomonas rhamnolipid biosurfactant on cell hydrophobicity and biodegradation of octadecane. Appl Environ Microbiol 60, 2101-2106.

Received 24 November 2000; revised 12 April 2001; accepted 1 June 2001. 